\title{
Understanding tectonic processes and their consequences: a tribute to A.M. Celâl Şengör: Part 2
}

\author{
Special Editors \\ John F. Dewey \\ University College, Oxford OX1 4BH, UK \\ Ali Polat \\ University of Windsor, Windsor, Ontario, Canada
}

